(2) Open Access Full Text Article

\title{
Dry year does not reduce invasive parasitic fly prevalence or abundance in Darwin's finch nests
}

This article was published in the following Dove Press journal:

Reports in Parasitology

2 October 2013

Number of times this article has been viewed

\section{Jennifer $\mathrm{AH}$ Koop ${ }^{1,2}$ \\ Céline Le Bohec ${ }^{1,3}$ \\ Dale H Clayton'}

'Department of Biology, University of Utah, Salt Lake City, UT, USA;

${ }^{2}$ Ecology and Evolutionary Biology, University of Arizona, Tucson, AZ,

USA; ${ }^{3}$ Centre Scientifique de Monaco, Laboratoire Européen Associé (LEA 647 'Biosensib'), Principality of Monaco
Correspondence: Jennifer AH Koop Department of Ecology and Evolutionary Biology, University of Arizona, PO Box 210088, Tucson, AZ 8572I, USA

$\mathrm{Tel}+\mathrm{I}$ 80I 6733862

Email jenniferkoop@email.arizona.edu
Abstract: The recent introduction of the parasitic nest fly Philornis downsi (Diptera: Muscidae) to the Galápagos Islands poses a serious threat to the bird species it infests, including Darwin's finches. Variation in climatic conditions, such as rainfall or drought, may influence fly populations and their effect on birds. We monitored the abundance of $P$. downsi in an extremely dry year in nests of the medium ground finch (Geospiza fortis). We fumigated nests to compare the reproductive success of birds in nests with and without flies. Neither the prevalence nor the abundance of $P$. downsi decreased significantly in the dry year compared with an earlier wet year for which we have already published data. Very few birds bred successfully under the dry conditions, independent of parasite prevalence and abundance. The low reproductive success of the finches presumably reflected limited food resources rather than parasites. Our sample sizes were low because few birds attempted to breed in the dry year. Nevertheless, our data indicate that $P$. downsi is capable of withstanding the extreme climatic fluctuations characteristic of the Galápagos Islands, which may contribute to the invasiveness of this parasite.

Keywords: breeding success, Geospiza fortis, invasive species, medium ground finch, parasitic fly

\section{Introduction}

Variability in temperature, humidity, and rainfall is known to alter interactions between hosts and their parasites. ${ }^{1-5}$ For example, low annual precipitation can decrease parasite prevalence (percentage of hosts infested) or abundance (number of parasites per host). For this reason, low precipitation may provide hosts with a temporary refuge from parasites. In contrast, low annual precipitation may lead to decreases in host conditions that could increase host susceptibility to parasitism. Thus, predicting the effect of invasive parasites on host populations requires an understanding of the effect of climatic fluctuation on parasite populations. ${ }^{6-8}$ Unfortunately, as this study shows, documenting the effects of dry years on a nest parasite population is difficult because few birds attempt to breed in dry years, making it challenging to locate adequate samples of nests for study.

The Galápagos Islands have a well-preserved bird fauna, with no recorded extinctions of endemic species, to date. ${ }^{9}$ However, the recent introduction of a parasitic nest fly, Philornis downsi, poses a threat to land bird species across the archipelago. Philornis downsi was discovered in nests of Darwin's finches and other species in the Galápagos in $1997 .{ }^{10}$ Since then, the parasite has been found on 12 of the 14 major islands and is known to parasitize at least 14 species of birds, including nine species of Darwin's finches. ${ }^{10,11}$ 
Adult flies are nonparasitic and feed on decaying organic matter. Philornis downsi lays its eggs in the nest material of birds (P Lincango, Charles Darwin Research Station, personal communication, June, 2013), and possibly directly into the nares (nostrils) of nestlings. ${ }^{12}$ Fly larvae hatch and live in the nest until they pupate in the nest material and emerge as adults. As they progress through three larval instars, $P$. downsi feed on the blood of nestlings and female adults. ${ }^{12,13}$ Such feeding causes reductions in nestling hematocrit, growth, and fledging success (reviewed in Koop et a ${ }^{14}$ ). Philornis downsi has been implicated in population declines of several Darwin's finch species. ${ }^{15-19}$

Variation in temperature, humidity, and precipitation is thought to affect the prevalence and abundance of parasites such as $P$. downsi. ${ }^{20-22}$ Although temperature in the Galápagos remains relatively constant, annual rainfall varies by several orders of magnitude. ${ }^{23,24} \mathrm{~A}$ given year consists of typical "wet" and "dry" seasons, with most of the year's rainfall occurring during the wet season. However, the duration and quantity of annual rainfall in the Galápagos is highly unpredictable. ${ }^{23}$ On the island of Santa Cruz, meteorological data collected during the last 60 years show that annual precipitation varied from 2,769 mm during a strong El Niño year to just $64 \mathrm{~mm}$ in an exceptionally dry year. ${ }^{25}$

Several studies suggest that the highly variable climate of the Galápagos affects $P$. downsi prevalence and intensity. Fessl et al ${ }^{12}$ suggest that different climatic conditions may have contributed to significant variation in the prevalence of P. downsi infesting small ground finch (Geospiza fuliginosa), medium ground finch, and cactus finch (G. scandens) nests among study years. Dudaniec et $\mathrm{al}^{21}$ examined the effect of annual rainfall on $P$. downsi intensity in the nests of several Darwin's finch species. Across all host species studied, P. downsi intensity (per nestling) differed significantly among years, being highest in an El Niño (wet) year. Huber ${ }^{26}$ found $64 \%$ prevalence of $P$. downsi in medium ground finch (G. fortis) nests during a dry year compared with $98 \%$ prevalence in the same population of finches in a wet year. A positive relationship between rainfall and parasite load also has been reported for other Philornis species. ${ }^{20,22}$ These studies suggest dry conditions could lead to decreases in P. downsi prevalence and abundance, with a consequent improvement in host reproductive success. Alternatively, dry years could conceivably limit the number of finch nests available to flies, such that each nest is attacked by a larger number of flies, on average. This, in turn, might lead to a more severe effect of $P$. downsi on the reproductive success of finches in a dry year. Fessl et $\mathrm{al}^{27}$ found $100 \%$ P. downsi prevalence in small and medium ground finch nests over the course of 2 years of study, both of which were relatively dry.

The goal of our study was to assess the possibility that a dry year might provide finches with a climatic refuge from the detrimental effects of $P$. downsi. We had two specific objectives: compare $P$. downsi prevalence and abundance in nests between a wet and dry year within the same population of finches, and simultaneously quantify the effect of P. downsi on finch breeding success in a dry year, using an experimental manipulation of parasite load.

\section{Materials and methods}

\section{Study area}

Our study was conducted January-April 2009 on the island of Santa Cruz, in the Galápagos Archipelago (Figure 1). Our field site, El Garrapatero, is a $1.5 \mathrm{~km}^{2}$ area in the arid, coastal zone. Medium ground finches are abundant at El Garrapatero, where they nest primarily in giant prickly pear cacti (Opuntia galapageia).$^{26}$ Clutch size ranges from $1-5$ eggs. Females incubate the eggs for 10-14 days, after which the nestlings hatch asynchronously during a 2- to 4-day-period. Nestlings spend another 10-14 days in the nest before fledging.

\section{Data collection}

We searched El Garrapatero for active medium ground finch nests. Active status was confirmed when a male and female built a nest or were seen entering a nest that had already been built. Active nests were visited every other day between the hours of 06:00 and 11:00, and the number of eggs and nestlings were recorded. New nestlings were marked individually by coloring a toenail with a permanent marker. When nestlings were at least 7 days of age, they were fitted with a numbered Monel metal band (National Band and Tag Co., Newport, KY, USA) and 3 plastic color bands. To help disentangle the potential effects of climate and parasites on finch breeding success, nests were alternately assigned to a fumigated or sham-fumigated treatment on the day the first nestling hatched. Fumigated nests were sprayed with a $1 \%$ permethrin solution (Permectrin $\mathrm{II}^{\odot}$; KMG Chemicals, Houston, TX, USA), a residual synthetic pyrethroid commonly used in agriculture, on the day the first nestling hatched, and then again 4 days later. Sham-fumigated nests were sprayed with water at the same times. Nestlings and eggs were removed, along with a thin layer of nesting material, from the bottom of the nest. The nests were given several minutes to dry, and then nesting material, eggs, and nestlings were returned to the nest. Parents were quick to return to nests 


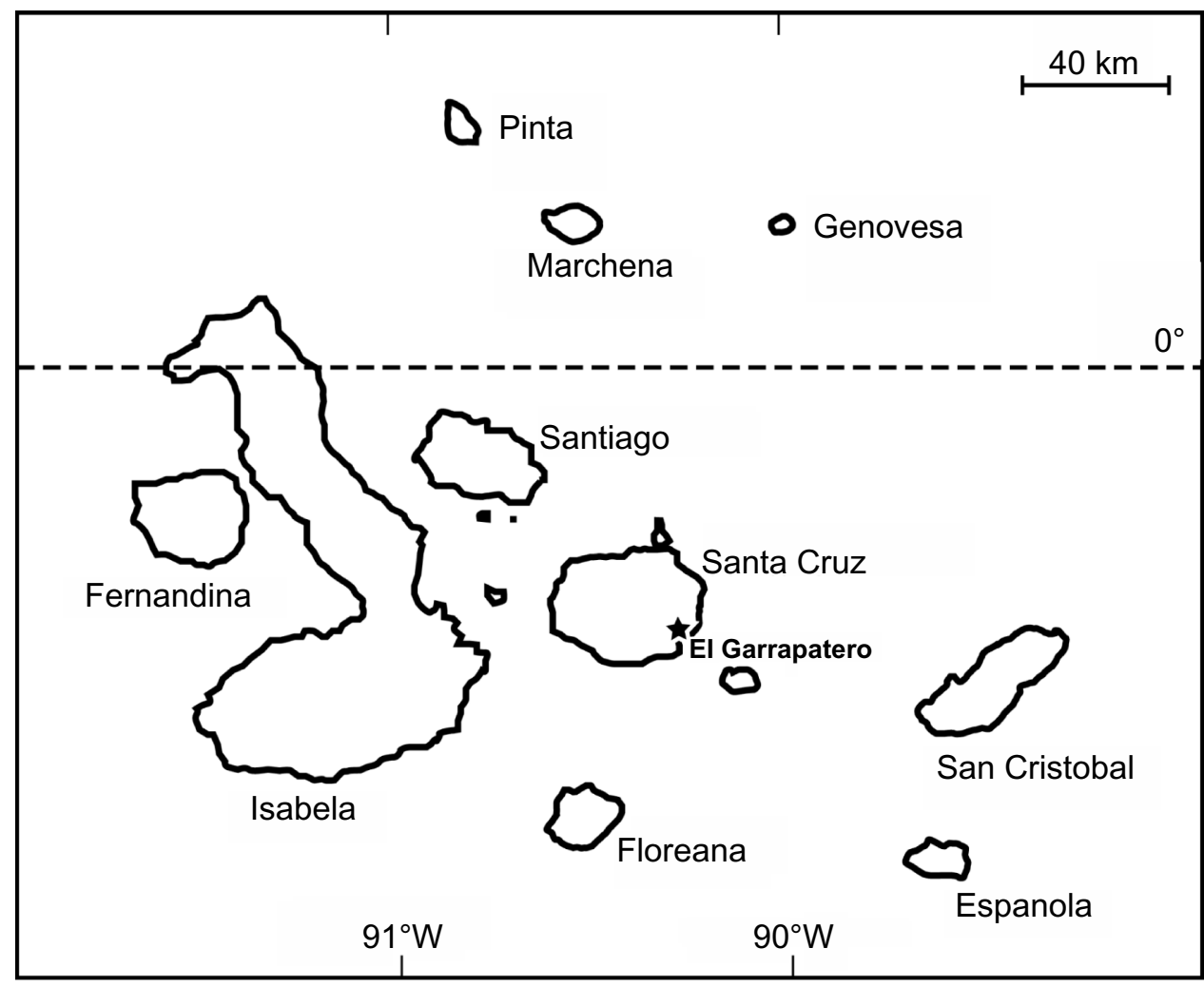

Figure I Map of Galápagos Islands. Fieldwork was conducted on Santa Cruz Island at El Garrapatero, indicated by the star.

after treatment, and no cases of nest abandonment resulting from treatment were observed.

We used a ladder to access the nests and examine the contents. Nests were visited until the oldest nestling was 10 days of age (or all nestlings had died). Visiting nests with nestlings older than 10 days can trigger premature fledging. ${ }^{28}$ Therefore, we observed nests with older nestlings from a distance, using binoculars, an easy task as the nests are domed structures with side entrances. Fledging was confirmed by observing and identifying birds on the basis of their color bands after they left the nest. ${ }^{14}$ Reproductive success for each treatment was the number of nests that fledged at least a single offspring.

After each nesting bout, we removed the nest and placed it in a sealed plastic bag. (Finches do not reuse nests between reproductive bouts or breeding seasons). ${ }^{24}$ The nest was carefully dissected within 8 hours of collection, and $P$. downsi larvae, pupae, and enclosed pupal cases were counted. First instar larvae are tiny and can live subcutaneously on nestlings, making them difficult to quantify reliably. Therefore, "total" parasite abundance was calculated as the sum of all second and third instar larvae, pupae, and enclosed pupal cases found either in the nest material or externally on dead nestlings. Parasite abundance was the number of parasites per nest. Parasite prevalence was the percent of infested nests out of all nests.

Monthly mean precipitation data were collected by a weather station at the Charles Darwin Research Station in Academy Bay, Puerto Ayora, Santa Cruz. ${ }^{25}$ Academy Bay is approximately 13 kilometers $(\mathrm{km})$ from El Garrapatero and at the same elevation; thus, weather patterns are comparable between the two sites. ${ }^{26}$

\section{Results}

Few birds bred during the dry year (2009), making it difficult to find active nests to study. After intensive daily searching, we managed to locate 13 active nests, of which seven were fumigated and six were sham-fumigated (with water). The treatment was effective: no P. downsi were found in nests that were fumigated, whereas sham-fumigated nests had a mean ( \pm 1 standard error) of $30.5 \pm 7.5$ parasites (Mann-Whitney $U=3.5 ; P=0.006$; Table 1).

There was no significant difference in the reproductive success of fumigated and sham-fumigated nests (Fisher's exact, $P=1.0$; Table 1). The number of nests producing at least a single fledgling was low for both treatments. Only one of the seven fumigated nests fledged any offspring. 
Table I Summary of breeding activities and parasite data for studies of medium ground finches performed in 2008 and 2009 at El Garrapatero, Santa Cruz Island

\begin{tabular}{|c|c|c|c|c|}
\hline & \multicolumn{2}{|l|}{2008} & \multicolumn{2}{|l|}{2009} \\
\hline & Lined & Unlined & Fumigated & Sham-fumigated \\
\hline \multicolumn{5}{|l|}{ Medium ground finch data } \\
\hline Finch nests, $\mathrm{n}$ & 24 & 24 & 7 & 6 \\
\hline Hatchlings (total), $\mathrm{n}$ & 75 & 67 & 15 & 14 \\
\hline Fledglings (total), $\mathrm{n}$ & 19 & 3 & 2 & 2 \\
\hline Nests with at least one fledgling, $n$ & 8 & I & I & I \\
\hline \multicolumn{5}{|l|}{ Philornis downsi data } \\
\hline Mean parasite abundance \pm standard error & $21.8 \pm 3.6$ & $37.5 \pm 4.9$ & $0 \pm 0$ & $30.5 \pm 7.5$ \\
\hline Parasite prevalence & $20 / 24(83 \%)$ & $23 / 24(96 \%)$ & $0 / 7(0 \%)$ & $5 / 6(83 \%)$ \\
\hline
\end{tabular}

Notes: The 2008 data are first reported in Koop et al. ${ }^{14}$ Parasite abundance is the sum of all second and third instar larvae, pupae, and enclosed pupal cases in nests. Parasite prevalence is the percentage of infested nests out of all nests. Nest liners were used in 2008 to prevent larvae from feeding on nestlings. ${ }^{14}$

In comparison, two of the six sham-fumigated nests fledged offspring; however, the fledglings from one of these were found on the ground immediately below the nest and were too weak to escape when approached. These birds could not have survived and were never observed later in the study. They therefore were not considered to have truly fledged. Fledglings from the other two nests (one fumigated, one sham-fumigated) were perched in bushes near the nest and moved to higher branches when approached.

We compared the 2009 data with previously published data collected from the same population of finches in 2008. ${ }^{14}$ Monthly mean precipitation during the finch breeding season (January-April) was significantly higher in 2008 than in 2009 (157.6 $\pm 47.6 \mathrm{~mm}$ versus $23.3 \pm 11.7 \mathrm{~mm}$, respectively; $t=2.74$; $P=0.034$; Figure 2A). Monthly mean humidity during the same period was significantly higher in 2008 than in 2009 (85.8\% \pm $0.3 \%$ relative humidity versus $80.1 \% \pm 1.4 \%$ relative humidity, respectively; $t=4.07 ; P=0.007$; Figure $2 \mathrm{~B}$ ). In contrast, monthly mean temperature did not differ significantly between the 2008 and 2009 breeding periods $\left(25.8^{\circ} \mathrm{C} \pm 0.5^{\circ} \mathrm{C}\right.$ in 2008 versus $26.2^{\circ} \mathrm{C} \pm 0.2^{\circ} \mathrm{C}$, respectively; $t=0.86, P=0.42$; Figure $2 \mathrm{C}$ ).

The prevalence of $P$. downsi in sham-fumigated nests did not differ significantly between 2008 and 2009 (Fisher's exact test, $P=0.37$; Table 1 and Figure 3A). Philornis downsi was present in 23 of 24 (96\%) sham-fumigated nests in 2008 compared with five of six (83\%) sham-fumigated nests in 2009. The abundance of $P$. downsi in sham-fumigated nests decreased slightly in 2009 but did not differ significantly from $2008(U=58.5 ; P=0.51$; Table 1; Figure 3B). Mean $P$. downsi abundance in sham-fumigated nests was $37.5 \pm 4.9$ in 2008 compared with $30.5 \pm 7.5$ in 2009 .

\section{Discussion}

As anticipated, given the low rainfall, far fewer birds bred in the dry year relative to wet years. ${ }^{24,26}$ Despite the decrease in breeding activity, we were able to monitor 13 medium ground finch nests to test the effects of dry conditions on parasite prevalence and abundance, and on finch reproductive success. Fumigated nests fared just as poorly as sham-fumigated nests, suggesting that dry conditions limited the ability of Darwin's finches to breed, independent of parasite pressure. Indeed, although the seven fumigated nests had no parasites, only one of these nests fledged any offspring. Decreases in the breeding success of other species of Darwin's finches in dry years have been documented ${ }^{24,26}$ and are attributed to the reduced availability of invertebrate food resources in dry years. ${ }^{23,24,29}$ As adults, medium ground finches mainly eat seeds, but during the breeding season, the finches feed invertebrates such as caterpillars to their nestlings. ${ }^{29}$ The effect of depleted food resources may be so strong in a dry year that any potential effect of parasitism is overshadowed.

The dry conditions in our 2009 study did not significantly alter the prevalence or abundance of $P$. downsi relative to the wetter conditions of $2008 .{ }^{14}$ Dudaniec et al ${ }^{21}$ found that $P$. downsi parasitizes nestlings at a higher intensity during years of heavy rainfall. However, the authors hypothesized that increases in host density during wet years might be driving the increases in parasite intensity, rather than rainfall itself. Other studies are mixed; some have reported no effect of host density on Philornis intensity, ${ }^{30}$ whereas others have reported that increases in host density led to decreases in fly intensity. ${ }^{22}$ We observed a dramatic difference in the number of breeding finches at the same site between years (Table 1). However, our comparisons of $P$. downsi prevalence and abundance between years indicate that the number of $P$. downsi in medium ground finch nests is not affected by host density, at least in our study.

In the Galápagos, there is a tendency for rainfall patterns to alternate in successive years; ${ }^{23}$ however, multiyear stretches of drought or heavy rainfall do occur. ${ }^{25}$ Our study 

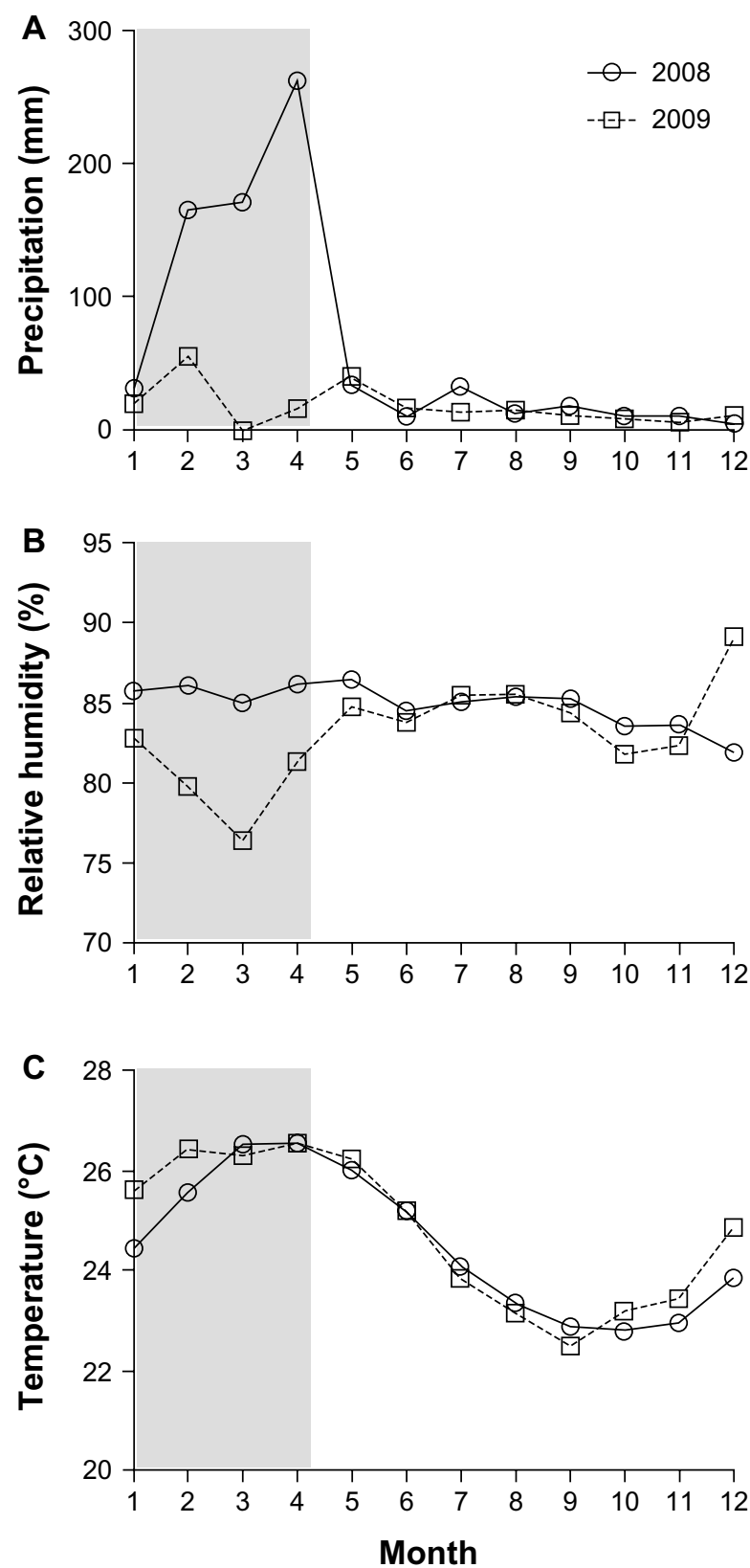

Figure 2 Mean monthly precipitation (A), relative humidity (B), and temperature (C) at El Garrapatero, Santa Cruz Island, Galápagos, in 2008 (circles, solid line) and 2009 (squares, dashed line). The typical medium ground finch-breeding season (January-April) at El Garrapatero is highlighted in gray.

compares data from a single dry breeding season with published data from a single wet breeding season the previous year at the same site. Although we found no significant effect of low rainfall on P. downsi abundance or prevalence within a single dry breeding season, several successive years of dry weather could have a more severe effect on $P$. downs $i$ populations. During extended periods of drought, populations of finches can forgo breeding altogether, ${ }^{31}$ which may have cascading effects on $P$. downsi populations, assuming they cannot breed in the absence of active finch nests.
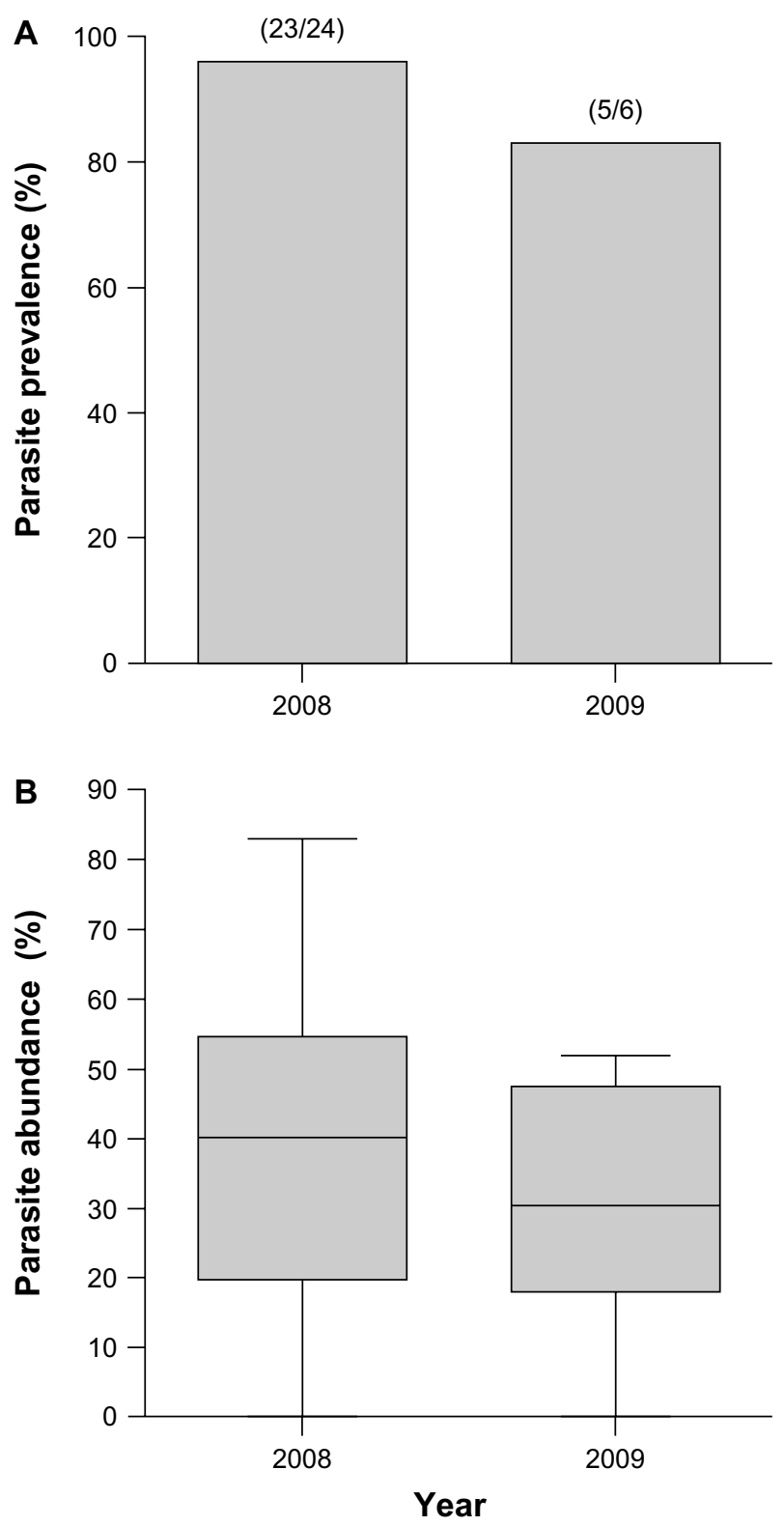

Figure 3 Comparison of Philornis downsi populations between wet (2008) and dry (2009) years. (A) Comparative prevalence of $P$. downsi in 2008 and 2009. Numbers above the bars show the proportion of parasitized nests with $P$. downsi larvae, pupae, and/or enclosed pupae for unlined (2008) and sham-fumigated (2009) nests. (B) Box-plots comparing P. downsi abundance in 2008 and 2009 among shamfumigated nests. Parasite abundance is quantified as the sum of all second and third instar larvae, pupae, and enclosed pupae in a nest.

The availability of alternate hosts may augment $P$. downsi populations in dry years. Philornis downsi is known to infest the nests of at least 14 species of birds in the Galápagos. ${ }^{10,11}$ Host species that are able to breed despite the dry conditions may provide a refuge for the flies when other hosts are unavailable. Moreover, the island of Santa Cruz consists of three major habitat zones, delineated primarily by elevation. Variation in rainfall patterns across habitat zones could allow birds to breed in the wet highland habitat, even if they cannot 
breed in the arid lowland habitat. Flies may also be able to move between islands to find breeding hosts; unfortunately, little is known about the mobility of $P$. downsi within or among islands. Dudaniec et $\mathrm{al}^{32}$ found little difference in the genetic population structure for $P$. downsi between habitats on Santa Cruz, suggesting a high level of gene flow. Further work is needed to determine whether fly movements are related to host availability.

Although somewhat unpredictable, dry years occur relatively frequently in the Galápagos. Dry years are known to deplete food resources and limit the number of Darwin's finches that are able to breed. ${ }^{24}$ These effects result in studies with low sample sizes that often go unpublished. Although we were not able to replicate our study in another dry year, our study is the first to report the effects of a dry year on $P$. downsi prevalence and abundance, in conjunction with a test of the effects of $P$. downsi on host reproductive success. The ability to predict the population dynamics of $P$. downsi depends on the gradual accumulation of information of this type during both wet and dry years.

\section{Acknowledgments}

We thank O Tiselma and R Clayton for help in the field. We thank the Charles Darwin Research Station for access to historical weather data records for Santa Cruz Island. We thank our anonymous reviewers, whose comments greatly improved the manuscript. This work was supported by a National Science Foundation grant (DEB-0816877) to Dale H Clayton, and a National Institutes of Health Postdoctoral Excellence in Research and Teaching Fellowship (K12-GM000708) and Sigma Xi Grants-in-Aid of Research to Jennifer AH Koop. All procedures were approved by the University of Utah Institutional Animal Care and Use Committee (protocol 07-08004) and by Galápagos National Park (PC-04-10: 0054411).

\section{Disclosure}

The authors report no conflicts of interest in this work.

\section{References}

1. Merino S, Potti J. Mites and blowflies decrease growth and survival in nestling pied flycatchers. Oikos. 1995;73:95-103.

2. Moyer BR, Drown DM, Clayton DH. Low humidity reduces ectoparasite pressure: implications for host life history evolution. Oikos. 2002;97(2):223-228.

3. Kutz SJ, Hoberg EP, Polley L, Jenkins EJ. Global warming is changing the dynamics of Arctic host-parasite systems. Proc Biol Sci. 2005;272(1581):2571-2576.

4. Bush SE, Harbison CW, Slager DL, Peterson AT, Price RD, Clayton DH. Geographic variation in the community structure of lice on western scrub-jays. J Parasitol. 2009;95(1):10-13.
5. Polley L, Thompson RC. Parasite zoonoses and climate change: molecular tools for tracking shifting boundaries. Trends Parasitol. 2009;25(6): 285-291.

6. Sutherst RW. The vulnerability of animal and human health to parasites under global change. Int J Parasitol. 2001;31(9):933-948.

7. Froeschke G, Harf R, Sommer S, Matthee S. Effects of precipitation on parasite burden along a natural climatic gradient in southern Africa - implications for possible shifts in infestation patterns due to global changes. Oikos. 2010;119(6):1029-1039.

8. Malenke JR, Newbold N, Clayton DH. Condition-specific competition governs the geographic distribution and diversity of ectoparasites. Am Nat. 2011;177(4):522-534.

9. Parker PG, Whiteman NK, Miller ER. Conservation medicine in the Galápagos Islands: Partnering behavioral, population and veterinary scientists. The Auk. 2006;123:625-638.

10. Fessl B, Tebbich S. Philornis downsi - a recently discovered parasite on the Galápagos archipelago - a threat for Darwin's finches? Ibis. 2002;144(3):445-451.

11. Wiedenfeld DA, Jimenez GA, Fessl B, Kleindorfer S, Valarezo JC. Distribution of the introduced parasitic fly Philornis downsi (Diptera, Muscidae) in the Galapagos Islands. Pac Conserv Biol. 2007;13(1): 14-19.

12. Fessl B, Sinclair BJ, Kleindorfer S. The life-cycle of Philornis downsi (Diptera: Muscidae) parasitizing Darwin's finches and its impacts on nestling survival. Parasitology. 2006;133:739-747.

13. Dodge HR. Revisional studies of flies of the genus Philornis Meinert (Diptera, Muscidae). Studia Entomologia. 1971;14:458-459.

14. Koop JA, Huber SK, Laverty SM, Clayton DH. Experimental demonstration of the fitness consequences of an introduced parasite of Darwin's finches. PLoS One. 2011;6(5):e19706.

15. Dvorak M, Vargas H, Fessl B, Tebbich S. On the verge of extinction: a survey of the mangrove finch Cactospiza heliobates and its habitat on the Galápagos Islands. Oryx. 2004;38(2):171-179.

16. Dvorak M, Fessl B, Nemeth E, Kleindorfer S, Tebbich S. Distribution and abundance of Darwin's finches and other land birds on Santa Cruz Island, Galápagos: evidence for declining populations. Oryx. 2012;46(1):78-86.

17. Grant PR, Grant BR, Petren K, Keller LF. Extinction behind our backs: the possible fate of one of the Darwin's finch species on Isla Floreana, Galápagos. Biol Conserv. 2005;122(3):499-503.

18. O'Connor JA, Sulloway FJ, Kleindorfer S. Avian population survey in the Floreana highlands: is Darwin's Medium Tree Finch declining in remnant patches of Scalesia forest? Bird Conserv Internat. 2010;20(4): 343-353.

19. O’Connor J, Sulloway FJ, Robertson J, Kleindorfer S. Philornis downsi parasitism is the primary cause of nestling mortality in the critically endangered Darwin's medium tree finch (Camarhynchus pauper). Biodivers Conserv. 2010;19:853-866.

20. Arendt WJ. Philornis ectoparasitism of pearly-eyed thrashers. II. Effects on adults and reproduction. The Auk. 1985;102(2):281-292.

21. Dudaniec RY, Fessl B, Kleindorfer S. Interannual and interspecific variation in intensity of the parasitic fly, Philornis downsi, in Darwin's finches. Biol Conserv. 2007;139(3-4):325-332.

22. Antoniazzi LR, Manzoli DE, Rohrmann D, Saravia MJ, Silvestri L, Beldomenico PM. Climate variability affects the impact of parasitic flies on Argentinean forest birds. J Zool. 2010;283(2):126-134.

23. Grant PR, Boag PT. Rainfall on the Galapagos and the demography of Darwin's finches. The Auk. 1980;97(2):227-244.

24. Grant PR. Ecology and Evolution of Darwin's Finches. Princeton, NJ: Princeton University Press; 1999.

25. Charles Darwin Foundation. Meteorological Database. Available from: http://www.darwinfoundation.org/datazone/climate/. Accessed November 19, 2012.

26. Huber SK. Effects of the introduced parasite Philornis downsi on nestling growth and mortality in the medium ground finch (Geospiza fortis). Biol Conserv. 2008;141(2):601-609. 
27. Fessl B, Kleindorfer S, Tebbich S. An experimental study on the effects of an introduced parasite in Darwin's finches. Biol Conserv. 2006;127:55-61.

28. Grant PR. Patterns of growth in Darwin's finches. Proc R Soc London B. 1981;212(1189):403-432.

29. Boag PT, Grant PR. Darwin's finches (Geospiza) on Isla Daphne Major, Galapagos: breeding and feeding ecology in a climatically variable environment. Ecol Monogr. 1984;54(4):463-489.

30. Le Gros A, Stracey CM, Robinson SK. Associations between northern mockingbirds and the parasite Philornis porteri in relation to urbanization. Wilson J Ornithol. 2011;123(4):788-796.
31. Grant PR, Grant BR. Demography and the genetically effective sizes of two populations of Darwin's finches. Ecology. 1992;73(3):766-784.

32. Dudaniec RY, Gardner MG, Kleindorfer S. Offspring genetic structure reveals mating and nest infestation behaviour of an invasive parasitic fly (Philornis downsi) of Galapagos birds. Biol Invasions. 2010;12: 581-592.
Reports in Parasitology

\section{Publish your work in this journal}

Reports in Parasitology is international, peer-reviewed, open access journal publishing original research, reports, reviews and commentaries on all areas of parasitology. The manuscript management system is completely online and includes a very quick and fair peer-review

\section{Dovepress}

system. Visit http:/www.dovepress.com/testimonials.php to read real quotes from published authors. 